\title{
Evaluation of the Chinese Government's Investment in Compulsory Education
}

\author{
Jinrui Wu \\ Tianjin University, Tianjin, China
}

\begin{abstract}
As children's human capital grows and they become more competitive in the job market as adults, universal compulsory schooling is becoming more prevalent. Education expenditures make for a significant portion of all financial expenditures in every country and area. This article will use China as the major study object, as well as the United States and Finland as case studies for comparison and analysis. Its goal is to investigate the ideal theoretical world and present personal ideas and improvement measures in the next article.
\end{abstract}

Key words: educational investment; human capital theory; economics of education; education mode; comparative education

\section{Introduction}

Education increases children's human capital and makes them more competitive in the labor market as adults, so universal compulsory education are becoming more and more common. In a general sense, compulsory education refers to the primary education provided by the government free of charge for children of a certain age through public schools(Hanushek, Welch, Machin and Woessmann, 2016). It differs from non-compulsory education in the following aspects: first, it is compulsory, that is, the government requires parents to keep their children in school for a certain number of years. Second, it is provided by the government for free, or parents and others do not pay the tuition directly, but pay the tuition indirectly through taxes. Nearly all countries require at least some mandatory schooling, and most of those countries provide that education for free. However, nothing is ever actually free. There is always an opportunity cost. The money and resources that go into education might be used to fund other social programs or bring down the debt. So many people wonder, is it necessary to spend time and money to get a higher education?

In every country and region, investment in education accounts for a large part of the financial expenditure. Some people think that the investment is too much, but more people think that the investment is worthwhile, not only for personal development but also for the economic development of the country. This paper introduces the problems of government-funded compulsory education in detail and analyzes the economic value of state investment in education by applying the principle of welfare economics(Anderberg, 2013). This article will take China as the primary research object, and also take the United States and Finland as the case for analysis and comparison, aims to explore the optimum theoretical world, and puts forward personal opinions and improvement measures in the following article.

\section{Economic Theory and Analysis}

Copyright $(\mathcal{C} 2021$ by author(s) and Frontier Scientific Research Publishing Inc.

This work is licensed under the Creative Commons Attribution International License (CC BY 4.0).

http://creativecommons.org/licenses/by/4.0/ 
According to the theory of public goods put forward by the American economist Samuel Samuelson, according to the degree of competition and exclusivity of products, all social goods can be divided into pure public goods, quasi-public goods and private goods(Samuelson, 1955). Among them, pure public goods have two characteristics: one is the nonexclusivity of consumption; that is, under the limitation of existing costs, existing consumers can not exclude others from consuming the product. Second, consumption is not competitive; that is, new consumers will not reduce the consumption level of the original consumers. Private products are exclusive and competitive products with consumption at the same time. Quasi-public goods, which are between pure public goods and private goods, are partly competitive and exclusive in consumption(Cabrillo, 2013).

The following part discusses the product attributes of compulsory education from the perspective of consumption. First of all, for educated individuals and their families, receiving compulsory education can improve the educated people's knowledge and lay a foundation for them to receive higher education levels(Wright and McMahan, 2011). In the long run, it can enable the educated people to obtain higher economic income and social status in the labor market and social activities. Secondly, to the whole society, compulsory education can promote the overall improvement of national quality, promote the sustained growth of the social economy and the harmonious development of society(Stephens and Yang, 2014). Compulsory education makes the educatees gain benefits personally, which cannot be shared by others. It is competitive and exclusive in a certain sense and has the property of personal products. Compulsory education brings benefits to the whole society, and all members of society can benefit from the development of the social economy. In this sense, compulsory education is not competitive and exclusive but has the nature of pure public goods(Xiao, Li and Zhao, 2017). Therefore, compulsory education has the nature of quasi-public goods and belongs to quasi-public goods.

Economic externalities are economic activities in which one economic entity produces or consumes economic activities that have a positive or negative impact on other economic entities, but for which it has not acquired a share, a reward or a price to pay. Among them, when producing favorable effect, be called a positive externality, produce unfavorable effect, be called a negative externality(van den Bergh, 2010). The positive externality is usually taken as the standard of public goods, and the higher the positive externality of a free product, the higher its public degree, the closer it is to pure public goods(Ciccone,2006). Compulsory Education has a robust positive externality, a person accepting compulsory education get great benefits, such as personal quality improvement(Liwiński, 2019). At the same time, the individual education level, the improvement of social labor productivity, help to improve the cultural level of society as a whole, and the level of economic development. The positive externalities of compulsory education products will become more substantial and more significant under the influence of government choice and institutional arrangement. From the above analysis, we can see that the non-competitive and non-exclusive nature of the compulsory education, as well as its vast positive externalities and the mandatory nature imposed by the government, determines that the government should be the main contributor to its significant funds, compulsory education plays a leading role in the provision of services(Wang,W, 2014). At the same time, because of the competitive and exclusive nature of the compulsory education, under the environment of the market economy, we can make full use of the functions of the market, give play to market advantages, and actively utilize market and other non-market subjects, promoting the continuous development of the compulsory education cause.

However, for some practical reasons, compulsory education is not a complete public good. Pure public goods refer to the non-competitive and non-exclusive goods or services in consumption(Zepke, N, 2010). Among them, non-competition refers to the additional consumption of a consumer does not reduce the utility of the original consumer. Noncompetitiveness means that producers do not have to produce additional goods or services for additional consumers. In 
other words, the marginal cost of providing goods or services to additional consumers is zero. Non-exclusivity refers to the inability of producers to technically exclude non-paying consumers, or the cost of exclusivity, while technically feasible, is too high to be worth the cost. Non-exclusivity means that private markets can not produce a sufficient quantity of public goods because private producers can not recover the costs of providing public goods. Therefore, pure public goods must be provided by the government.

Compulsory education is not purely public good. The reason for this is that, on one hand, the marginal cost of providing educational services to the additional children will not be zero as the number of students increases, and on the other hand(Zepke, N, 2010), however the compulsory education does not charge fees, the number of teachers, classrooms and teaching equipment will increase accordingly, but this free non-exclusivity is not dictated by technology or prohibitive costs. Schools can easily exclude non-paying children if they want to. Education is a kind of individual product with positive externalities, that is, the benefits of education can not be completely internalized by the educated or their families, and society can get some benefits from it. This kind of individual product with positive externalities is often called a quasipublic product. Because the family's optimal decision is made according to the marginal private income equals to the marginal (private) cost, and the society's optimal decision requires the marginal social income equals to the marginal (social) cost. As a result, under private arrangements, parents will buy less education for their children than is socially optimal in terms of the marginal social benefits of education. However, market failure caused by externalities does not mean that the market must be replaced by the government, if the government subsidizes the cost of education in schools or the cost of education in families, the private market can also, in theory, achieve a socially optimal amount of education. As a result, compulsory education is not the only option for market failures caused by externalities.

Selfishness on the part of parents can also lead to primary education market failure (Bruce, 1998). This view holds that because of the asymmetry between the costs and benefits of education, that is, the parents bear the costs and the children receive the benefits, some parents who calculate the immediate benefits may not provide their children with adequate educational opportunities. When this happens, not only do children not get the educational benefits they deserve, but society suffers as well. Because less educated children are more likely to become adults dependent on social assistance and more likely to commit deviant or criminal acts than those with sufficient education, this undoubtedly adds to the cost to taxpayers(Lin,Li, 2009). Therefore, the government's provision of compulsory education benefits not only these children but society as a whole. However, addressing the lack of demand for education caused by parents' selfishness does not necessarily require the government to provide free education. It would be easier for the government to enact laws that would force parents to buy a certain amount of education for their children. In this way, we can also understand the origin of compulsory education.

\section{Problems with Compulsory Education in China}

In the compulsory education period, miscellaneous expenses, books expenses and living expenses account for a considerable proportion of the residents' expenses, and the compulsory education's financial input is the critical problem that perplexes the development of compulsory education(Tsang, M.C.and Ding, 2005) On December 24, 2005, the State Council issued the circular on deepening the reform of the funding guarantee mechanism for rural compulsory education, which calls the gradual inclusion of rural compulsory education in the scope of public financial guarantee, establishing a mechanism for ensuring the proportional sharing of rural compulsory education funds by central and local sub-projects. In the fall of 2008, tuition and fees for urban compulsory education students will be fully waived, and compulsory education funds will be fully covered by the state financial guarantee nationwide(Wright and McMahan, 2011). Since the implementation of the reform of the funding guarantee mechanism for rural compulsory education, the overall input of 
compulsory education has increased continuously and has achieved specific results. However, because our country is still in the primary stage of socialism, the national financial resources are limited, the fund input is still seriously insufficient, the fund input is not balanced and so on, also becomes the prominent contradiction in the reform process. This can be seen in the following two aspects.

\subsection{Overall funding is inadequate}

Compulsory education is the foundation for the development of national education and the continuous improvement of national quality. The state of a country's investment in compulsory education reflects the importance and importance that the government attaches to compulsory education. At present, China's educational objects account for $20 \%$ of the world's total, while educational funds only account for $1 \%$ of the world's total(Liu Yang, 2009). Among these public educational funds, only about $3 \%$ of the educational funds are spent on compulsory and compulsory education(Hongju, W, 2008). Our government lags far behind the developed world and other developing countries in compulsory education spending. This level of investment is bound to affect the quality and level of China's compulsory education development, for rural areas, a direct impact on China's new socialist rural construction and development.

\subsection{Compulsory education is not balanced in funding}

At present, there are two aspects in the imbalance of compulsory education investment in China: one is a regional imbalance. Compared with the developed areas in the east, the economic development level of the central and western regions is relatively low, and the investment in education is seriously inadequate. In the long run, the backward level of the compulsory education affects the quality of human capital; it would have a negative impact on the Midwestern Sectional Figure Skating Championships' economic development, leaving it unable to invest more in compulsory education, creating a vicious circle. On the other hand, it is the imbalance between urban and rural areas. There are 200 million primary and secondary school students in China, of which 150 million are in rural areas, which are the focus and difficulty of compulsory education. In rural areas, the per compulsory education budget for public spending is only about $30 \%$ of the urban average(Wu,F ,2008). The majority of poor students in our country are rural students. The situation of rural children out of school and dropping out of school is still difficult. Besides, the rural teachers' income level is low, the rural school infrastructure is backward, the teaching equipment is obviously insufficient and the situation is familiar.

\section{Cases of the United States and Finland}

Compulsory education can be understood as a way for the government to intervene in the market allocation of educational resources from a fair point of view, so that every child, especially those from low-income families, can enjoy equal opportunities in the availability of necessary educational resources. Here, the availability of free education is essential to ensure that children overcome the inequalities of opportunity created by the poverty of their parents. However, there is no denying that family origin and other factors also have a significant influence on children's educational level.

In America, the government pays for primary and secondary public education and heavily subsidizes college. In 2015 the federal and state governments will spend about $\$ 634$ billion on primary and secondary education. That is an average of about $\$ 12,500$ per student each year, which is much money. However, educational inequality is also prevalent in the United States. "All Americans want a fair education, but the American education system is simply not fair." said Betsy Devos, the secretary of education(Disare,M, 2017). Equity issues, she argues, are not confined to universities but also the primary and secondary education system. Robert Shapiro, a professor of government at Columbia University, told reporters that the most significant advantage of the wealthy is that parents can provide better primary and secondary education. Hence their children know more about the college application system and how to take advantage of opportunities than students from poorer backgrounds. Because of the lack of adequate education funds, many students from low-income 
families in the United States are deterred from higher education, which makes the United States miss out on many of the best talents of the future.

Unlike other countries, Finland's education system was rated as the "fairest". About $6.5 \%$ of Finland's GDP goes to public education, far higher than the average in the western developed world. The Finnish government provides most of the funding for the 20 universities, which can also be managed independently. Meanwhile the central and local governments are jointly responsible for funding 28 institutes of technology. So all Finns go to school for free, whether it is essential education or higher education. The government pays for textbooks, transport and lunches, with the central government paying 57 per cent and the local authorities 43 per cent(Morgan, H. 2014). This decision has lasted for decades and has not changed with the change of political parties. Among OECD countries, Finland is one of the most efficient users of educational resources. In most countries, higher education students receive the most money on average; Finland, by contrast, spends an average of $\$ 8,200$ per pupil on primary and secondary school, the highest of all school ages.

\section{Deviations from the 1st Best}

According to the deviations from 1st best, the government's investment in compulsory education is essentially state intervention, especially in terms of funds, to help students gain the right to receive education, to compete fairly, to train high-quality talents and to promote the development of the national economy. State intervention occurs because the current state of the market deviates from the ideal market(Barr, 1992). For countries and students, the ideal market would be for all regions to have comparable schools and education funding, so that students have the right for education, no matter where they come from or what economic conditions they have. Although at present, the investment and development of compulsory education are not balanced, and it is challenging to reach this ideal state, the concept of compulsory education has been proposed to move towards an ideal education system.

\section{Implications and Suggestions}

According to some problems in the process of national investment in compulsory education, and after studying the educational models in the United States and Finland, I have some reflections on the development of China's compulsory education.

(1) Strengthen government control and maintain the growth trend of funding for compulsory education. Education is a kind of state power and responsibility. Compared with the market, the government plays a more significant role in regulating and allocating resources for compulsory education. Governments of all countries should pay more attention to fairness in their policies and institutional arrangements for compulsory education.

(2) Give full play to the function of market resource allocation. The quasi-public goods attribute of compulsory education and its strong positive externality determine that the main body of its investment should be diversified and focused(Cabrillo, 2013). The diversification of the subject of compulsory education is the only way to realize the balanced and healthy development of compulsory education in all countries.

(3) To promote a balanced compulsory education. China should strive to address the current imbalance between urban and rural economic and educational development. More money is being poured into poor areas to change the harsh realities there and promote balanced development between urban and rural areas. This is conducive to promoting educational equity, improving access to education for students in poor areas, raising the level of knowledge of rural residents, and promoting social stability and economic development.

\section{Conclusions}

In a word, education plays a crucial role in economic development. Education promotes the optimization of human capital. Human resources constitute the basic elements of national wealth, while capital and natural resources are only 
passive factors of production. Workforce is a decisive factor to accumulate capital, utilize natural resources, construct economic organization and promote national development. At the same time, it is accepted that the higher the level of education, the greater the educational content of human capital and the more significant the contribution to productivity. Statistical studies show a strong correlation between employees' education and their income. Higher education is associated with higher income. This fact is enough to give credence to the idea that educational attainment plays a vital role in increasing productivity. Therefore, the government should increase investment and develop compulsory education. From the economic point of view, it can promote the development of national economic level and increase productivity; from the non-economic point of view, it can promote social equity and maintain social stability(Cabrillo, 2013). Therefore, the government should strive to build a fair education system. The Chinese government should learn from Finland, invest more in education, raise the level of compulsory education and higher education, and build an ideal education system.

\section{Conflicts of Interest}

The author declares no conflicts of interest regarding the publication of this paper.

\section{References}

[1] Anderberg, D. (2013). Post-compulsory Education: Participation and Politics. European Journal of Political Economy, (29):134-150.

[2] Barr, N. (1992). Economic Theory and the Welfare State: A Survey and Interpretation. American Economic Association.

[3] Cabrillo, F. (2013). Constitutional Economics And Public Institutions. Cheltenham: Edward Elgar.

[4] Ciccone, A. \& Peri, G. (2006). Identifying Human-Capital Externalities: Theory with Applications, Review of Economic Studies Ltd.

[5] Disare, M. (2017). Linda Darling-Hammond on the Future of New York Education-and What She Makes of Betsy Devos. Prakken Publications, Inc, Ann Arbor.

[6] Hanushek, E., Welch, F., Machin, S. and Woessmann, L. (2016). Handbook Of The Economics Of Education. Volume 5. Amsterdam: North-Holland.

[7] Hongju, W. (2008). The Characteristics of China's Compulsory Education Funding Policy Change(1986-2006). Brill, Netherlands.

[8] Lin, T. (2009). Intra-provincial Inequality in Financing Compulsory Education in China: Exploring the Role of Provincial Leaders (1994-2001). Taylor \& Francis Group.

[9] Linster, B.G. (1998). An Evolutionary Explanation for Rotten Kids. Blackwell Publishing Ltd, Oxford, UK.

[10] Liu, Y. \& Fang, Y. (2009). Basic Education Reform in China: Globalization with Chinese Characteristics. Asia Pacific Journal of Education, 29(4):407-412.

[11] Liwiński, J. (2019). The Impact of Compulsory Education on Employment and Wages in a Transition Economy. Eastern European Economics, (58):137-173.

[12] Morgan, H. (2014). The Education System in Finland: A Success Story other Countries Can Emulate. Association for Childhood Education International, Olney.

[13] Samuelson, P. (1955). Professor Samuelson on Operationalism in Economic Theory: Comment. The Quarterly Journal of Economics, (69):310.

[14] Stephens, M. and Yang, D. (2014). Compulsory Education and the Benefits of Schooling. American Economic Review, (104):1777-1792.

[15] Tsang, M.C. \& Ding, Y. (2005). Resource Utilization and Disparities in Compulsory Education in China. The 
Chinese University Press.

[16] Van den Bergh, J. (2010) . Externality or Sustainability Economics. Ecological Economics, (69): 2047-2052.

[17] Wang, W. (2014). Decomposing Inequality in Compulsory Education Finance in China: 1998-2008, Southern Public Administration Education Foundation. Inc, Harrisburg.

[18] Wright, P. and McMahan, G. (2011). Exploring Human Capital: Putting 'Human' back into Strategic Human Resource Management. Human Resource Management Journal, (21):93-104.

[19] Wu, F., Zhang, D. \& Zhang, J. (2008). Unequal Education, Poverty and Low Growth-a Theoretical Framework for Rural Education of China. Elsevier India Pvt Ltd.

[20] Xiao, Y., Li, L. and Zhao, L. (2017). Education on the Cheap: The Long-run Effects of a Free Compulsory Education Reform in Rural China. Journal of Comparative Economics, (45):544-562.

[21] Zepke, N., Leach, L. \& Butler, P. (2010). Engagement in Post-compulsory Education: Students' Motivation and Action. Routledge.

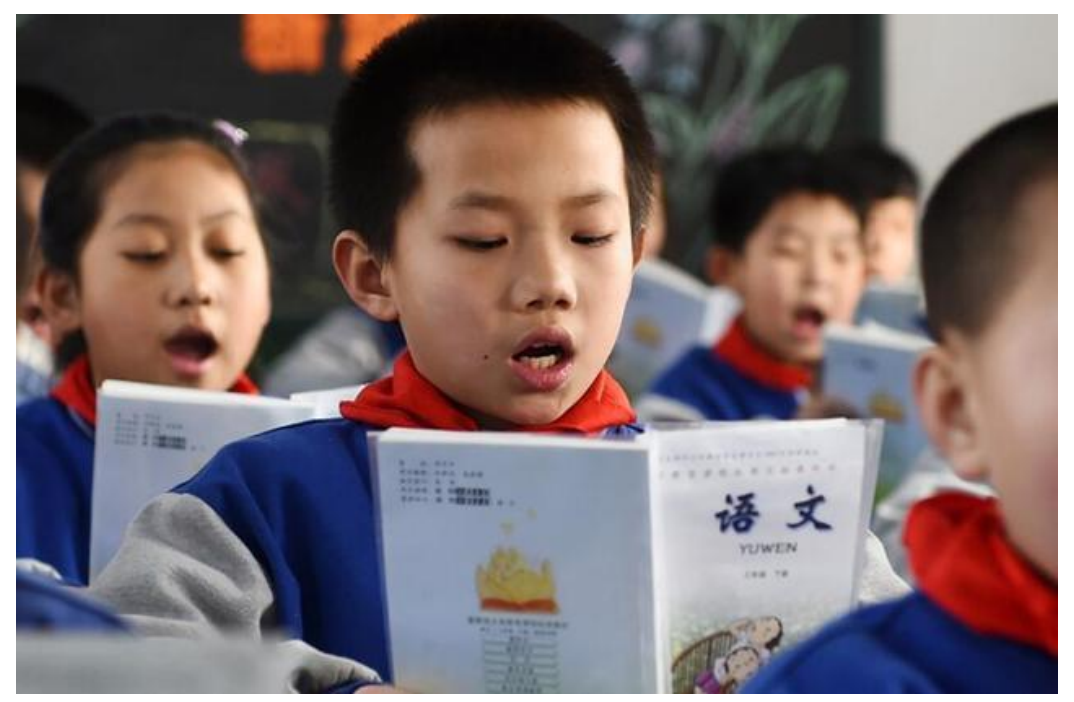

